\title{
Distinct Effect of Stress on 11ß-Hydroxysteroid Dehydrogenase Type 1 and Corticosteroid Receptors in Dorsal and Ventral Hippocampus
}

\author{
P. ERGANG ${ }^{1}$, A. KUŽELOVÁ ${ }^{2}$, M. SOTÁK ${ }^{1}$, P. KLUSOŇOVÁ ${ }^{1}$, J. MAKAL $^{2}$, J. PÁCHA ${ }^{1,2}$ \\ ${ }^{1}$ Institute of Physiology Academy of Sciences of the Czech Republic, Prague, Czech Republic, \\ ${ }^{2}$ Department of Physiology, Faculty of Science, Charles University, Prague, Czech Republic
}

Received June 10, 2013

Accepted October 7, 2013

On-line January 8, 2014

\begin{abstract}
Summary
Multiple lines of evidence suggest the participation of the hippocampus in the feedback inhibition of the hypothalamuspituitary-adrenal axis during stress response. This inhibition is mediated by glucocorticoid feedback due to the sensitivity of the hippocampus to these hormones. The sensitivity is determined by the expression of glucocorticoid (GR) and mineralocorticoid (MR) receptors and 11ß-hydroxysteroid dehydrogenase type 1 (11HSD1), an enzyme that regulates the conversion of glucocorticoids from inactive to active form. The goal of our study was to assess the effect of stress on the expression of $11 \mathrm{HSD} 1, \mathrm{GR}$ and MR in the ventral and dorsal region of the CA1 hippocampus in three different rat strains with diverse responses to stress: Fisher 344, Lewis and Wistar. Stress stimulated 11 HSD1 in the ventral but not dorsal CA1 hippocampus of Fisher 344 but not Lewis or Wistar rats. In contrast, GR expression following stress was decreased in the dorsal but not ventral CA1 hippocampus of all three strains. MR expression was not changed in either the dorsal or ventral CA1 region. These results indicate that (1) depending on the strain, stress stimulates 11HSD1 in the ventral hippocampus, which is known to be involved in stress and emotion reactions whereas (2) independent of strain, stress inhibits GR in the dorsal hippocampus, which is predominantly involved in cognitive functions.
\end{abstract}

\section{Key words}

11ß-hydroxysteroid dehydrogenase - Stress - Hippocampus • Corticosteroid receptors

\section{Corresponding author}

J. Pácha, Institute of Physiology, Academy of Sciences of the Czech Republic, Vídeňská 1083, 14220 Prague 4-Krč, Czech Republic. Fax: +420 24106 2488. E-mail: pacha@biomed.cas.cz

\section{Introduction}

Stressful situations generate profound physiological and behavioral disturbances. Firstly, the stressor-related information from the sensory systems is conveyed to the brain where the situation is processed and forwarded to the hypothalamus. These signals lead to the activation of two output systems - the sympatho-adrenomedullary and hypothalamic-pituitaryadrenocortical (HPA) axes. The HPA axis is controlled by the parvocellular neurons in the paraventricular nucleus but also by stress excitatory and inhibitory circuits that are activated by stressors in various brain structures including the hippocampus, amygdala and prefrontal cortex (Ulrich-Lai and Herman 2009). Activation of the HPA axis induces the release of corticosteroids that self-regulate the activation and responsiveness of the HPA axis through a negative feedback mechanism (Kolber et al. 2008). Once released, corticosteroids are able to influence the brain through rapid non-genomic (Groeneweg et al. 2011) and slower, long-lasting genomic pathways in which they bind to high-affinity mineralocorticoid (MR) and lower-affinity glucorticoid receptors (GR) (de Kloet et al. 1998, Herbert et al. 2006). Whereas GRs are expressed throughout the brain, MRs have a distribution that is predominantly restricted to the central amygdala, gyrus dentatus and hippocampal subregions CA3 and especially CA1 (de Kloet et al. 1998).

The response of the target cells to corticosteroids depends not only on their plasma level and receptor density, but also on the pre-receptor metabolism, which determines the intracellular concentration of the 
biologically active hormone. This metabolism converts cortisol and corticosterone from their inert 11-oxo forms (cortisone, 11-dehydrocorticosterone) and thus amplifies the local action of the hormone (for a review, see Herbert et al. 2006, Wyrwoll et al. 2011). This amplification

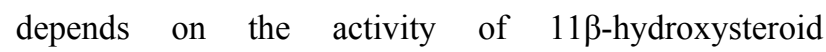
dehydrogenase type I (11HSD1), an enzyme that is highly expressed in various brain structures, including the hippocampus (Rajan et al. 1996).

Numerous studies indicate that a number of stress-associated conditions affect hippocampal memory and plasticity, that the hippocampus inhibits the activity of the HPA axis and that corticosteroids play an important role in these processes (Herman et al. 2005, Herbert et al. 2006, Kim et al. 2006). For example, mice carrying a deletion of the GR in the cerebral cortex and hippocampus but retaining GR expression in the paraventricular nuclei have a delayed shut-off of HPA axis responses to stressors (Furay et al. 2008). Chronic stress in the hippocampus influences the number and functioning of GR (Joël et al. 2007) and acute stress modulates the expression of GR and MR genes (Paskitti et al. 2000). However, it is unknown whether the hippocampus modulates the expression of 11HSD1 when a situation is perceived as stressful. The aim of this study was therefore to determine the effect of stress on the expression of hippocampal 11HSD1 and to find out whether the genetic background can modulate the response of 11HSD1 to stress. Three different rat strains with differing levels of stress responsivity were used: Fisher 344 (F344), Lewis (LEW) and Wistar (WIS) rats. LEW rats display a markedly smaller HPA reactivity to a wide range of physical, psychological and immunological stressors and different expression of GR and MR compared with the F344 rats, which have a very reactive HPA axis (Sternberg et al. 1989, Smith et al. 1994, Dhabhar et al. 1995, Oitzl et al. 1995, Monček et al. 2001). Since LEW rats are inbreeds derived from WIS rats, we chose WIS rats as the appropriate comparative strain.

\section{Materials and Methods}

\section{Animals and stress procedure}

Naïve male WIS (Inst. of Physiology, Prague), LEW and F344 rats (both Charles River, Germany), 6-8 weeks of age were initially housed in groups of three or four in polypropylene cages for three weeks to acclimatize to the laboratory prior to any manipulations.
The animals were kept under controlled conditions $\left(23 \pm 1^{\circ} \mathrm{C}\right.$, lights on between 6:00 and 18:00 h) with free access to rat chow pellets and tap water. To elicit a stronger stress response, we employed a variable stress protocol consisting of 3 days of tandem exposures to various stressors according to Tsoory and Richter-Levin (2006). On the first day, the animals were exposed to a forced swim for $10 \mathrm{~min}$ that was carried out in an opaque cylindrical water tank (diameter $0.3 \mathrm{~m}$; height $0.5 \mathrm{~m}$; water depth $0.3 \mathrm{~m}$; water temperature $22 \pm 1{ }^{\circ} \mathrm{C}$ ), on the second day they were placed on an elevated platform $(15 \times 15 \mathrm{~cm}$ at a height of $70 \mathrm{~cm}$ above floor level) for three $30 \mathrm{~min}$ trials with a $60 \mathrm{~min}$ inter-trial interval and on the third day the rats were immobilized for $2 \mathrm{~h}$ in a plastic box. After the last stress session, the rats were immediately anesthetized with isoflurane and blood was collected by cardiac puncture, then the animals were killed by decapitation, the brain removed and promptly frozen. All animal experiments and tissue collections were carried out between 9 a.m. and 1 p.m., the rats of the various strains being evenly distributed across this period. The experiments were approved by the Animal Care and Use Committee of the Institute of Physiology.

\section{Brain sampling and processing}

Brain sampling and processing was performed as previously described (Švec et al. 2010) with some modifications. Briefly, serial $12 \mu \mathrm{m}$ frozen brain sections were prepared on a cryostat. Selected sections were adhered onto slides coated with polyethylene naphthalate membrane (Leica Microsystems, Wetzlar, Germany), placed in $95 \%$ ethanol, stained with $4 \%$ cresyl violet acetate and washed three times in $95 \%$ ethanol. The dorsal and ventral parts of the CA1 subregion (dCA1, vCA1) of the hippocampus were dissected using a LMD6000 Laser Microdissection System (Leica) and captured into the caps of the microcentrifuge tubes (average area of brain tissue: $0.25 \mathrm{~mm}^{2}$ ). The stereotaxic coordinates for the hippocampus were $-4.92 \mathrm{~mm}$ from the bregma (mediolateral axis: \pm 4.0 for $\mathrm{dCA} 1$ and \pm 5.0 for vCA1; dorsoventral axis: \pm 3.0 for $\mathrm{dCA} 1$ and \pm 8.0 for vCA1) as defined by Paxinos and Watson (2007). The dissected tissue was homogenized in $75 \mu$ l of RTL buffer (Qiagen, Hilden, Germany) and stored at $-80^{\circ} \mathrm{C}$.

Extraction of total RNA was performed using a RNeasy Micro Kit (Qiagen, Hilden, Germany) following the manufacturer's instruction and RNA was evaluated with a NanoDrop spectrophotometer 
(NanoDrop Products, Wilmington, DE, USA). Reverse transcription was performed with Enhanced Avian Reverse Transcriptase (Sigma-Aldrich, St. Louis, MO, USA). The cDNA samples were analyzed by real-time PCR in a Viia 7 Sequence Detection System (Life Technologies, Foster City, CA, USA) using TaqMan Gene Expression Master Mix and TaqMan Assays (Life Technologies, Carlsbad, CA, USA) specific for rat 11HSD1 (cat. no. Rn01461862_m1) and mineralocorticoid (cat. no. Rn00565562_m1) and glucocorticoid receptors (cat. no. Rn00561369_m1). The housekeeping gene, glyceraldehyde-3-phosphate dehydrogenase (GAPDH; TaqMan Endogenous Control, cat. no. 4352338), was used to normalize mRNA expression. This gene was chosen because its transcript is not changed in the rat brain during stress (Porterfield et al. 2011). The data were analyzed using the standard curve method.

\section{Plasma corticosterone measurement}

Blood was centrifuged, plasma collected and stored at $-20{ }^{\circ} \mathrm{C}$ until analysis. Plasma concentrations of corticosterone were quantified using a commercially available rat corticosterone radioimmunoassay kit (MP Biomedicals, Solon, OH, USA) according to the manufacturer's instructions. Assays were conducted in a single run to prevent inter-assay variability; the intraassay variability was less than $10 \%$.

\section{Statistical analysis}

All data are expressed as means \pm SEM. The data were analyzed with a two-way ANOVA (Statistica 6.1., StatSoft Inc., Tulsa, OK, USA) for the effect of genotype (between-subject factor) and treatment (withinsubject factor) and their interactions. As no interactions between these two factors were found in any studied parameter (11HSD1, MR, GR, plasma corticosterone), the $p$ values are not given in Results. Post-hoc analyses were performed using the Student-Newman-Keuls test. The value $\mathrm{p}<0.05$ was considered statistically significant.

\section{Results}

To account for possible differences in the effect of our stress paradigm in WIS, LEW and F344 rats, plasma corticosterone levels were determined in control unstressed animals and in stressed rats immediately after the last stress session. Two-way ANOVA revealed a significant effect of stress $(F[1,36]=54.72 ; p<0.001)$ but there was no significant effect of genotype $(\mathrm{F}[2,36]=1.36$, n.s.). A post-hoc analysis indicated that the plasma corticosterone of stressed WIS, LEW and F344 rats was significantly higher than that of the control unstressed group (Table 1).

Table 1. Effect of stress on plasma levels of corticosterone in Wistar, Fisher 344 and Lewis rats.

\begin{tabular}{llc}
\hline & \multicolumn{2}{c}{ Corticosterone (ng/ml) } \\
\cline { 2 - 3 } & \multicolumn{1}{c}{ CTRL } & Stress \\
\hline Wistar & $26.3 \pm 6.7(8)$ & $289.3 \pm 73.6^{* *}(8)$ \\
Fisher 344 & $51.2 \pm 17.9(8)$ & $361.1 \pm 34.5^{* *}(8)$ \\
Lewis & $78.0 \pm 4.7(6)$ & $213.2 \pm 34.6^{*}(7)$ \\
\hline
\end{tabular}

Results are expressed as means \pm SEM; numbers of animals are given in parentheses. Statistically significant differences are indicated: ${ }^{*} \mathrm{P}<0.05$ and ${ }^{* *} \mathrm{P}<0.001$ compared with the values of control unstressed animals (CTRL).

To determine whether stress might be associated with changes in hippocampal sensitivity to corticosterone, we measured the expression of 11HSD1, GR and MR in the ventral and dorsal CA1 hippocampus. For all measurements, a $3 \times 2$ ANOVA was examined using genotype (strains WIS, LEW, F344) and stress conditions (control vs. stress) or hippocampal regions (CA1 ventral vs. CA1 dorsal) as variables. For all measurements, stress conditions or hippocampal regions did not significantly interact with rat strain, so the following discussion will focus on the main effects of strain, stress conditions and hippocampal regions. Exposure to a three-day stress resulted in a significant effect on the expression of hippocampal $11 \mathrm{HSD} 1$ in the ventral $(\mathrm{F}[1,32]=6.47$; $\mathrm{p}<0.05)$ but not dorsal hippocampus $(\mathrm{F}[1,36]=0.88$; n.s. $)$. In addition, there was a significant effect of genotype for the ventral $(\mathrm{F}[2,32]=6.02 ; \mathrm{p}<0.05)$ but not dorsal hippocampus $\quad(\mathrm{F}[2,36]=0.13$; n.s. $)$ A post-hoc comparison (Fig. 1) showed that the ventral CA1 region of control unstressed animals of F344 and LEW strains had a significantly lower expression of 11HSD1 than WIS rats (F344: $p<0.01$; LEW: $p<0.05)$ and that stress significantly increased 11HSD1 expression in F344 rats $(p<0.05)$, whereas the effect in LEW rats was just shy of statistical significance $(p=0.07)$; no changes were observed in the WIS strain. The expression of GR in the dorsal hippocampus was altered by stress $(\mathrm{F}[1,36]=35.78$; $\mathrm{p}<0.001)$ but did not depend on genotype $(\mathrm{F}[2,36]=2.55$; n.s.). In contrast, genotype $(\mathrm{F}[2,35]=11.61 ; \mathrm{p}<0.001)$ but 
not stress $(F[1,35]=1.34$; n.s. $)$ significantly affected $M R$ expression in the dorsal hippocampus. As depicted in Figure 2, a marked decrease in GR expression was observed in the dorsal CA1 hippocampus of all three rat strains exposed to stress (WIS, LEW: $\mathrm{p}<0.01$; F344: $\mathrm{p}<0.05)$. The post-hoc analysis also revealed that the CA1 region of the dorsal hippocampus exhibited a significantly greater expression of MR in control WIS rats than in F344 and LEW (both $\mathrm{p}<0.01$ ). In contrast, neither stress nor genotype influenced the expression of GR (stress: $F[1,34]=1.12$; n.s.; genotype: $F[2,34]=1.75$; n.s.) and $\mathrm{MR}$ (stress: $\mathrm{F}[1,33]=0.01 ;$ n.s.; genotype: $\mathrm{F}[2,33]=2.89$; n.s.) in the ventral hippocampus (Fig. 2).

Moreover, the analysis performed to compare differences between the dorsal and ventral CA1 hippocampus found significantly different expression of all studied transcripts in control animals, i.e. 11HSD1 $(F[1,32]=30.93 ; p<0.001)$, GR $(F[1,33]=80.20 ; p<0.001)$ and $\mathrm{MR}(\mathrm{F}[1,32]=69.47 ; \mathrm{p}<0.001)$. A post-hoc analysis revealed that the dorsal hippocampus had a higher expression of $11 \mathrm{HSD} 1, \mathrm{GR}$ and MR than the ventral hippocampus of all three rat strains $(p<0.05$ or $p<0.001)$. Differences in the expression of 11HSD1, MR and GR expression in the dorsal and ventral CA1 hippocampus were also significantly pronounced in rats that had been exposed to stress (11HSD1: $F[1,34]=16.55 ; \mathrm{p}<0.001$; MR: $F[1,36]=68.99 ; \quad \mathrm{p}<0.001 ; \quad \mathrm{GR}: \quad \mathrm{F}[1,36]=53.41$; $\mathrm{p}<0.01)$. Post-hoc testing indicated that the 11HSD1 expression levels of the dorsal hippocampus were significantly higher than that of the ventral region in F344 $(\mathrm{p}<0.01)$ and LEW $(\mathrm{p}<0.05)$ but not in WIS rats (n.s.). Similarly, a post-hoc analysis for MR and GR showed a significantly higher expression of both receptors in the dorsal compared to the ventral hippocampus of all three rat strains (MR: $\mathrm{p}<0.01$ or $\mathrm{p}<0.001$; GR $\mathrm{p}<0.001$ ).
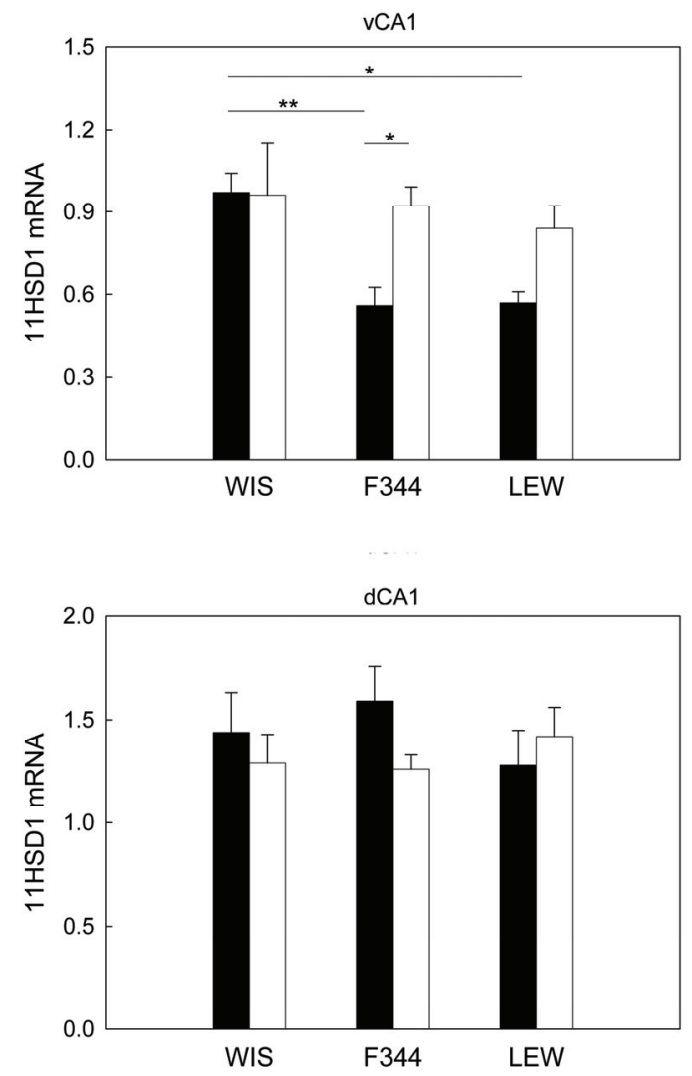

Fig. 1. Effect of stress on expression of $11 \mathrm{HSD} 1$ in CA1 region of ventral (vCA1) and dorsal (dCA1) hippocampus of stressed (open bars) and unstressed (filled bars) Wistar (WIS), Fisher 344 (F344) and Lewis (LEW) rats. Data are expressed as means \pm SEM (6-8 animals per group). Significant differences are indicated: ${ }^{*} \mathrm{P}<0.05$ and ${ }^{* *} \mathrm{P}<0.01$.

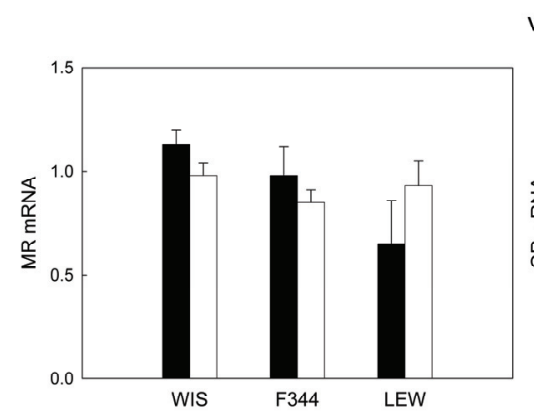

vCA1

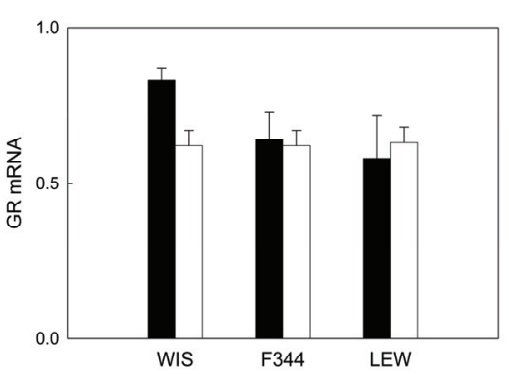

dCA1
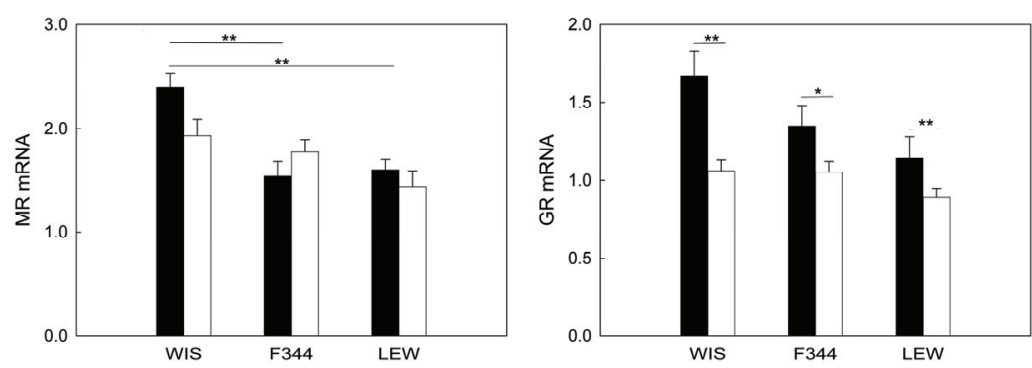

Fig. 2. Effect of stress on expression of mineralocorticoid (MR) and glucocorticoid (GR) receptors in CA1 region of ventral (vCA1) and dorsal (dCA1) hippocampus of stressed (open bars) and unstressed (filled bars) Wistar (WIS), Fisher 344 (F344) and Lewis (LEW) rats. Data are expressed as means \pm SEM (6-8 animals per group). Significant differences are indicated: ${ }^{*} \mathrm{P}<0.05$ and ${ }^{* *} \mathrm{P}<0.01$. 


\section{Discussion}

In this study we have presented novel data indicating regional differences in the regulation of $11 \mathrm{HSD} 1, \mathrm{GR}$ and $\mathrm{MR}$ in the dorsal and ventral CA1 hippocampus, and have characterized the response of these areas to stress in three rat strains that differ in their HPA reactivity and stress response. The hippocampus richly expresses both corticosteroid receptors and 11HSD1 (Herbert et al. 2006) and thus changes in the expression of GR/MR or 11HSD1 during stress might modulate the sensitivity of the hippocampus to corticosteroids. Indeed, two lines of evidence suggest that this may be sufficient to influence hippocampal functions. First, the increased GR gene dosage is associated with an enhanced resistance to stress (Reichardt et al. 2000) whereas a reduction in GR gene dosage leads to a prolonged activity of the HPA axis during stress (Ridder et al. 2005). Second, the deletion of 11HSD1, a glucocorticoid-producing enzyme, modulates the sensitivity of the HPA axis (Harris et al. 2001) and hippocampal overexpression of 11HSD2, a glucocorticoid-degrading enzyme, attenuates the negative impact of an excessive elevation of glucocorticoids on synaptic transmission and spatial memory (Dumas et al. 2010).

The key finding in this study is that 11HSD1 expression is increased by stress in the hippocampus, i.e. in the limbic structure that is activated by stress (UlrichLai and Herman 2009), and that this increase depends on the hippocampal region and genotype of the rat. The finding of increased 11HSD1 in the ventral but not dorsal CA1 region is of particular interest. Emerging evidence indicates that the ventral hippocampus is connected to stress and emotion whereas the dorsal hippocampus performs primarily cognitive functions (Fanselow and Dong 2010). The increase in 11HSD1 in our study is consistent with a previous study of the effect of arthritic stress on the undivided rat hippocampus (Low et al. 1994) but not with the effect of psychosocial stress on the hippocampus of tree shrews (Jamieson et al. 1997). The reason for this discrepancy is unknown, but might reflect a species-specific control of 11HSD1 or the type of stress. The putative role of corticosteroid status in the regulation of 11HSD1 is also supported by the finding of reduced hippocampal 11HSD1 mRNA and enzyme activity in adrenalectomized rats that can be reversed by substitution therapy of the glucocorticoid agonist (Low et al. 1994). As hippocampal cells reactivate inactive 11-dehydrocorticosterone to active corticosterone (Rajan et al. 1996), it can be hypothesized that the increase in 11HSD1 during stress might intensify the glucocorticoid signaling in the hippocampus. The increased transcript level of 11HSD1 in stressed F344 but not WIS and LEW rats suggests that F344 may amplify the hippocampal glucocorticoid signal more effectively than the stressed WIS and LEW rats, or that the positive effect of stressful stimuli on 11HSD1 requires a longer stress exposure in the WIS and LEW strain. This is in accordance with the well known hyperresposiveness of F344 rats to stressful stimuli.

As described in other studies, corticosteroids have been shown to act as structural and functional modulators of the hippocampus, a structure that modifies the negative feedback effect of glucocorticoids following stressful stimuli via the neural inhibition of stress responses (Feldman and Weidenfeld 1999, de Kloet et al. 2005, Herbert et al. 2006). Our results showed that the dorsal hippocampus had a higher expression of GR and that stressed rats had consistently suppressed GR mRNA in the dorsal but not ventral CA1 hippocampus of all three strains. This implies a potential attenuation of glucocorticoid signaling in the dorsal CA1 hippocampus, i.e. in the area that is involved in cognitive functions but not in regulation of the HPA axis (Fanselow and Dong 2010). In addition, the decreased expression of GR in the dorsal CA1 hippocampus is in agreement with the findings of previous studies in which chronic stress decreased hippocampal GR mRNA (Paskitti et al. 2000) and this effect did not depend on the responsiveness of the strain to stress (Gomez et al. 1996). In contrast to GR, the expression of MR was neither influenced by stress in the dorsal nor ventral region of CA1. Similarly, neither acute nor chronic stress modulated the expression of hippocampal MR mRNA in an in situ hybridization study (Paskitti et al. 2000). These findings could be understood in light of the differences between GR and MR. In rats, MRs have an approximately tenfold higher affinity for corticosterone than GR (de Kloet et al. 1998), which means that GR and MR are occupied in different ways. MRs are extensively occupied under basal unstressed conditions, while the saturation of GRs requires higher corticosterone levels that are usually reached in stressful situations.

In summary, the results of this study suggest inhomogeneous expression of 11HSD1, GR and MR in the dorsal and ventral CA1 hippocampus and indicate that glucocorticoid signaling in the CA1 region is regulated 
by stress through different mechanisms. Whereas in the dorsal area of CA1 the decreased expression of GR without any changes in 11HSD1 and MR expression indicates a stress-induced downregulation of glucocorticoid signaling, the increase in 11HSD1 expression without any changes in GR and MR in the ventral part of CA1 indicates an amplification of glucocorticoid signaling. The increased 11HSD1 in ventral CA1 might participate in the inhibitory feedback mechanisms of the HPA axis, whereas the attenuated GR expression in dorsal CA1 might play a role in ameliorating the negative effect of glucocorticoid excess on hippocampal plasticity, learning and memory. This conclusion is supported by the finding of reduced glucocorticoid negative feedback in mice lacking 11HSD1 (Harris et al. 2001) and by the finding of facilitated spatial learning in the moderately stressful water maze after hippocampal injection of the GR antagonist (Oitzl et al. 1998).

\section{Conflict of Interest}

There is no conflict of interest.

\section{Acknowledgements}

This work was supported by grant P303/10/0969 (to J. P.) from Czech Science Foundation and by grants 6187/2012 (to A. K.) and 5366/2012 (to J. M.) from Charles University.

\section{References}

DE KLOET ER, VREUGDENHIL E, OITZL MS, JOËLS M: Brain corticosteroid receptor balance in health and disease. Endocr Rev 19: 269-301, 1998.

DE KLOET ER, JOËLS M, HOLSBOER F: Stress and the brain: from adaptation to disease. Nat Rev Neurosci 6: 463-475, 2005.

DHABHAR FS, MCEWEN BS, SPENCER RL: Stress response, adrenal steroid receptor levels and corticosteroidbinding globulin levels - a comparison between Sprague-Dawley, Fischer 344 and Lewis rats. Brain Res 616: 89-98, 1993.

DHABHAR FS, MILLER AH, MCEWEN BS, SPENCER RL: Differential activation of adrenal steroid receptors in neural and immune tissues of Sprague Dawley, Fischer 344, and Lewis rats. J Neuroimmunol 56: 77-90, 1995.

DUMAS TC, GILLETTE T, FERGUSON D, HAMILTON K, SAPOLSKY RM: Anti-glucocorticoid gene therapy reverses the impairing effects of elevated corticosterone on spatial memory, hippocampal neuronal excitability, and synaptic plasticity. $J$ Neurosci 30: 1712-1720, 2010.

FANSELOW MS, DONG HW: Are the dorsal and ventral hippocampus functionally distinct structures? Neuron $\mathbf{6 5}$ : 7-19, 2010.

FELDMAN S, WEIDENFELD J: Glucocorticoid receptor antagonists in the hippocampus modify the negative feedback following neural stimuli. Brain Res 821: 33-37, 1999.

FURAY AR, BRUESTLE AE, HERMAN JP: The role of the forebrain glucocorticoid receptor in acute and chronic stress. Endocrinology 149: 5482-5490, 2008.

GÓMEZ F, LAHMAME A, DE KLOET ER, ARMARIO A: Hypothalamic-pituitary-adrenal response to chronic stress in five inbred rat strains: differential responses are mainly located at the adrenocortical level. Neuroendocrinology 63: 327-337, 1996.

GROENEWEG FL, KARST H, DE KLOET ER, JOËLS M: Rapid non-genomic effects of corticosteroids and their role in the central stress response. $J$ Endocrinol 209: 153-167, 2011.

HARRIS HJ, KOTELEVTSEV Y, MULLINS JJ, SECKL JR, HOLMES MC: Intracellular regeneration of glucocorticoids by $11 \beta$-hydroxysteroid dehydrogenase (11ß-HSD)-1 plays a key role in regulation of the hypothalamic-pituitary-adrenal axis: analysis of $11 \beta$-HSD-1-deficient mice. Endocrinology 142: 114-120, 2001.

HERBERT J, GOODYER IM, GROSSMAN AB, HASTINGS MH, DE KLOET ER, LIGHTMAN SL, LUPIEN SJ, ROOZENDAAL B, SECKL JR: Do corticosteroids damage the brain? J Neuroendocrinol 18: 393-411, 2006.

HERMAN JP, OSTRANDER MM, MUELLER NK, FIGUEIREDO H: Limbic system mechanisms of stress regulation: hypothalamo-pituitary-adrenocortical axis. Prog Neuropsychopharmacol Biol Psychiatry 29: 1201$1213,2005$. 
JAMIESON PM, FUCHS E, FLUGGE G, SECKL JR: Attenuation of hippocampal 11 $\beta$-hydroxysteroid dehydrogenase type 1 by chronic psychosocial stress in the tree shrew. Stress 2: 123-132, 1997.

JOËLS M, KARST H, KRUGERS HJ, LUCASSEN PJ: Chronic stress: implications for neuronal morphology, function and neurogenesis. Front Neuroendocrinol 28: 72-96, 2007.

KIM JJ, SONG EY, KOSTEN TA: Stress effects in the hippocampus: Synaptic plasticity and memory. Stress 9: 1-11, 2006.

KOLBER BJ, WIECZOREK L, MUGLIA LJ: Hypothalamic-pituitary-adrenal axis dysregulation and behavioral analysis of mouse mutants with altered glucocorticoid or mineralocorticoid receptor function. Stress 11: 321-338, 2008.

LOW SC, MOISAN MP, NOBLE JM, EDWARDS CR, SECKL JR: Glucocorticoids regulate hippocampal $11 \beta$-hydroxysteroid dehydrogenase activity and gene expression in vivo in the rat. J Neuroendocrinol $\mathbf{6}$ : 285-290, 1994.

MONČEK F, KVETNANSKÝ R, JEŽOVÁ D: Differential responses to stress stimuli of Lewis and Fischer rats at the pituitary and adrenocortical level. Endocr Regul 35: 35-41, 2001.

OITZL MS, VAN HAARST AD, SUTANTO W, DE KLOET ER: Corticosterone, brain mineralocorticoid receptors (MRs) and the activity of the hypothalamic-pituitary-adrenal (HPA) axis: the Lewis rat as an example of increased central MR capacity and a hyporesponsive HPA axis. Psychoneuroendocrinology 20: 655-675, 1995.

OITZL MS, FLUTTERT M, DE KLOET ER: Acute blockade of hippocampal glucocorticoid receptors facilitates spatial learning in rats. Brain Res 797: 159-162, 1998.

PASKITTI ME, MCCREARY BJ, HERMAN JP: Stress regulation of adrenocorticosteroid receptor gene transcription and mRNA expression in rat hippocampus: time-course analysis. Brain Res Mol Brain Res 80: 142-152, 2000.

PAXINOS G, WATSON C: The Rat Brain in Stereotaxic Coordinates. Elsevier, Amsterdam, 2007.

PORTERFIELD VM, ZIMOMRA ZR, CALDWELL EA, CAMP RM, GABELLA KM, JOHNSON JD: Rat strain differences in restraint stress-induced brain cytokines. Neuroscience 188: 48-54, 2011.

RAJAN V, EDWARDS CR, SECKL JR: 11 $\beta$-Hydroxysteroid dehydrogenase in cultured hippocampal cells reactivates inert 11-dehydrocorticosterone, potentiating neurotoxicity. J Neurosci 16: 65-70, 1996.

REICHARDT HM, UMLAND T, BAUER A, KRETZ O, SCHÜTZ G: Mice with an increased glucocorticoid receptor gene dosage show enhanced resistance to stress and endotoxic shock. Mol Cell Biol 20: 9009-9017, 2000.

RIDDER S, CHOURBAJI S, HELLWEG R, URANI A, ZACHER C, SCHMID W, ZINK M, HÖRTNAGL H, FLOR H, HENN FA, SCHÜTZ G, GASS P: Mice with genetically altered glucocorticoid receptor expression show altered sensitivity for stress-induced depressive reactions. J Neurosci 25: 6243-6250, 2005.

SMITH CC, OMELJANIUK RJ, WHITFIELD HJ, AKSENTIJEVICH S, FELLOWS MQ, ZELAZOWSKA E, GOLD PW, STERNBERG EM: Differential mineralocorticoid (type 1) and glucocorticoid (type 2) receptor expression in Lewis and Fischer rats. Neuroimmunomodulation 1: 66-73, 1994.

STERNBERG EM, YOUNG WS, BERNARDINI R, CALOGERO AE, CHROUSOS GP, GOLD PW, WILDER RL: A central nervous system defect in biosynthesis of corticotropin-releasing hormone is associated with susceptibility to streptococcal cell wall-induced arthritis in Lewis rats. Proc Natl Acad Sci USA 86: 4771-4775, 1989.

ŠVEC J, ERGANG P, MANDYS V, KMENT M, PÁCHA J: Expression profiles of proliferative and antiapoptotic genes in sporadic and colitis-related mouse colon cancer models. Int J Exp Pathol 91: 44-53, 2010.

TSOORY M, RICHTER-LEVIN G: Learning under stress in the adult rat is differentially affected by 'juvenile' or 'adolescent' stress. Int J Neuropsychopharmacol 9: 713-728, 2006.

ULRICH-LAI YM, HERMAN JP: Neural regulation of endocrine and autonomic stress responses. Nat Rev Neurosci 10: 397-409, 2009.

WYRWOLL CS, HOLMES MC, SECKL JR: 11ß-hydroxysteroid dehydrogenases and the brain: from zero to hero, a decade of progress. Front Neuroendocrinol 32: 265-286, 2011. 